
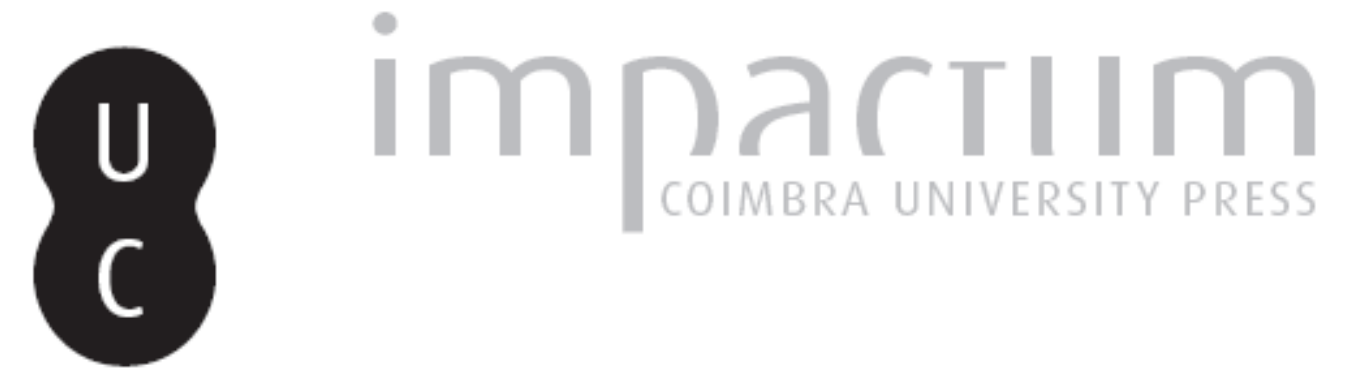

\title{
A Institutione del Prencipe Christiano (1543) de Mambrino Roseo da Fabriano numa tradução portuguesa do século XVI
}

\author{
Autor(es): Buescu, Ana Isabel
}

Publicado por: Imprensa da Universidade de Coimbra

URL persistente:

URI:http://hdl.handle.net/10316.2/42445

DOI:

DOl:https://doi.org/10.14195/0870-8584_0_2

Accessed : $\quad$ 26-Apr-2023 10:34:24

A navegação consulta e descarregamento dos títulos inseridos nas Bibliotecas Digitais UC Digitalis, UC Pombalina e UC Impactum, pressupõem a aceitação plena e sem reservas dos Termos e Condições de Uso destas Bibliotecas Digitais, disponíveis em https://digitalis.uc.pt/pt-pt/termos.

Conforme exposto nos referidos Termos e Condições de Uso, o descarregamento de títulos de acesso restrito requer uma licença válida de autorização devendo o utilizador aceder ao(s) documento(s) a partir de um endereço de IP da instituição detentora da supramencionada licença.

Ao utilizador é apenas permitido o descarregamento para uso pessoal, pelo que o emprego do(s) título(s) descarregado(s) para outro fim, designadamente comercial, carece de autorização do respetivo autor ou editor da obra.

Na medida em que todas as obras da UC Digitalis se encontram protegidas pelo Código do Direito de Autor e Direitos Conexos e demais legislação aplicável, toda a cópia, parcial ou total, deste documento, nos casos em que é legalmente admitida, deverá conter ou fazer-se acompanhar por este aviso.

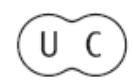




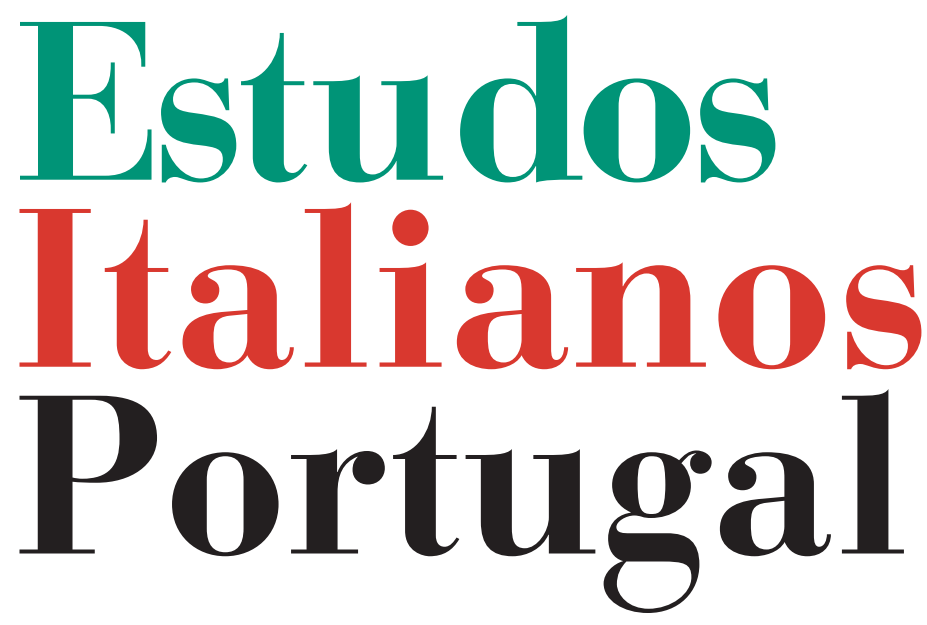

Instituto

Italiano

de Cultura

de Lisboa

Nova Série

$\mathrm{N}^{\mathbf{0}} \mathbf{0}$ 


\title{
A INSTITUTIONE DEL PRENCIPE CHRISTIANO (1543) DE MAMBRINO ROSEO DA FABRIANO NUMA TRADUÇÃO PORTUGUESA DO SÉCULO XVI
}

\author{
Ana Isabel Buescu
}

Em Valladolid era publicado, em 1529, o Libro llamado Relox de Príncipes, da autoria de Frei Antonio de Guevara, iniciando-se " [...] la más fantástica carrera y reputación literaria del siglo XVI, tanto dentro como fuera de España [...]" . A história do Relox de Príncipes está intimamente ligada à edição, cerca de um ano antes, em Sevilha, nos prelos de Jacobo Cromberger, sem nome de autor, do Libro Áureo de Marco Aurelio, também da autoria de Guevara. Com efeito, a parte mais importante desta última obra viria a integrar a publicação "oficial" de 1529, facto que originaria, de resto, uma persistente confusão entre as duas obras, até porque

${ }^{1}$ Francisco Márquez Villanueva e Augustin Redondo, "Burlas y veras en fray Antonio de Guevara", in Historia y crítica de la literatura española, dirigida por Francisco Rico, T. II, Siglos de oro: Renacimiento, dirigido por Francisco López Estrada, Barcelona, 1980, p. 173. O título desta primeira edição, que convém referir pelas variações a que foi sujeito, é o seguinte: Libro llamado relox de príncipes enel qual va encorporado el muy famoso libro de Marco aurelio: auctor devn libro y del otro: que es el muy reuerêdo padre fray Antonio de gueuara predicador $y$ coronista de su magestad: y agora nuenamête electo en obispo de Guadix el auctor auisa al lector: que lea primero los prologos: si querê entêder los libros. Desta primeira edição, raríssima, existe um exemplar na B. N. L. (Res. 294 A), que consultámos, e que pertenceu, segundo anotação manuscrita, à "Livraria cõmua da Carthuxa de Évora". No fim (fol. CCCXIXV ${ }^{\circ}$ ): "Liuro da Cartuxa de scala coeli de que o illmº e rmº Sñor D. Theotonio de Bargança [sic] [1578-1602] Arcebispo de Euora fundador da mesma casa lhe fes doação". 
aquela que pode considerar-se a versão primitiva, o Libro Aureo, continuaria a ser objecto de sucessivas edições autónomas ${ }^{2}$, apesar do aparente repúdio do autor ${ }^{3}$. De facto, segundo afirmação explícita de Guevara no prólogo do Relox de Príncipes, a impressão do Marco Aurelio fora feita sem seu consentimento. Após referir que, a pedido do imperador Carlos V, que se encontrava doente na altura, lhe entregara o manuscrito incompleto do Libro Áureo, Guevara afirma a sua mágoa por, sem poder controlar esse processo, o manuscrito ter sido copiado e recopiado na corte pelas mais diversas mãos, e progressivamente adulterado, publicando-se uma versão na qual não se reconhecia.

Consistia o Libro Áureo de Marco Aurélio, obra em que Guevara, como ele próprio testemunha ${ }^{4}$, começara a trabalhar em 1518, na vida romanceada do imperador-filósofo, erigido como modelo do príncipe virtuoso. A figura de Marco Aurélio é, neste sentido, explicitamente proposta por Guevara para verdadeiro modelo do jovem Carlos V, de quem Guevara era conselheiro e eventualmente cronista ${ }^{5}$.

2 Sobre as circunstâncias de gestação do Libro Áureo de Marco Aurelio (1528) e do Relox de Príncipes (1529), e as relações entre ambas as obras, v., por todos, Augustin Redondo, Antonio de Guevara (1480?-1545) et l'Espagne de son temps. De la carrière officielle aux oeuvres politico-morales, Genebra, 1976, particularmente III Parte, cap. IX, pp. 465-522.

3 Antonio de Guevara, Libro Avreo del gran emperador Marco Avrelio, con el relox de Príncipes. Compvesto por el muy Reverendo, y magnifico señor Don Antonio de Guevara, Obispo de Guadix, Predicador, y Coronista del Señor Emperador Carlos Quinto, Madrid, 1658, Prologo general, fol. 17v-18. Todas as citações serão feitas a partir desta edição, que denominaremos de Relox de Príncipes, para estabelecer a necessária distinção com o Libro Áureo de Marco Aurelio propriamente dito.

4 Relox de Príncipes, Prologo general, ed. cit., fol. $17 \mathrm{v}$.

5 "A este sabio Filosofo, y noble Emperador, tome Vuestra Magestad por ayo en su mocedad, por padre en su gouernacion, por adalid en sus guerras, por guion en sus jornadas, por amigo en sus trabajos, por exemplo en sus virtudes, por maestro en sus sciencias, por blanco en sus deseos, y por competidor en sus hazañas". Ibidem, fol. 12v-13. 
A obra de Guevara nada tinha a ver, no entanto, com o então praticamente desconhecido imperador Marco Aurélio, figura histórica que a Europa culta viria a redescobrir alguns anos mais tarde. Como faz notar René Costes, autor do único estudo de conjunto sobre a figura e a obra de Antonio de Guevara até surgir, já nos anos setenta, a obra de Augustin Redondo, "C'est en 1558 que Guillaume Xylander publia, d'après un manuscrit de la Palatine de Heidelberg et sur l'indication du bibliophile Conrad Gessner, le recueil authentique des Pensées de Marc-Aurèle"6.

Com efeito, o Libro Áureo constitui, no seu conjunto, uma efabulação a que Guevara dá foros de verosimilhança, ao apontar como fonte "histórica" principal um precioso códice da biblioteca de Cosme de Médicis em Florença ${ }^{7}$, em que se teria baseado para contar a vida daquele imperador romano. Essa e outras "fontes" são, na realidade, invenção de Guevara, e como foi já definitivamente demonstrado ${ }^{8}$, as obras em que de facto se baseou reduzem-se a alguns textos de autores latinos menores; tudo o resto, desde autores, a obras, deuses, datas e situações, é adaptado, forjado, ou inventado por Guevara ${ }^{9}$. A estratégia criadora de Guevara viria a ser decisiva na apreciação crítica do conjunto da sua obra ${ }^{10}$.

${ }^{6}$ René Costes, Antonio de Guevara. Son oeuvre (Bibliothèque de l'Ecole des Hautes Etudes hispaniques, X, 2), Bordéus, 1926, p. 41. O primeiro volume, sobre a vida de Guevara, foi publicado no ano anterior.

7 V. Augustin Redondo, op. cit., p. 473.

8 Por René Costes, ponto de vista confirmado por Augustin Redondo, op. cit., pp. 471-472.

${ }^{9}$ Veja-se, pelo carácter de síntese que reveste, a apreciação crítica de Menéndez y Pelayo sobre Guevara: "Todos los libros profanos de fray Antonio de Guevara, sin excepción alguna, están llenos de citas falsas, de autores imaginarios, de personajes fabulosos, de leyes apócrifas, de anécdotas de pura invención y de embrollos cronológicos y geográficos que pasman y confunden. Aun la poca verdad que contienen está entretejida de tal modo con la mentira que cuesta trabajo discernirla. Tenía, sin duda el ingeniosísimo fraile una vasta y confusa lectura de todos los autores latinos y griegos que hasta entonces se 
O Libro Áureo compreende uma "biografia" de Marco Aurélio, construída nos moldes que enunciámos, seguida de um conjunto de cartas apócrifas, que Guevara atribui a Marco Aurélio. A figura do imperador, tal como é reconstruída por Guevara, surge na dupla dimensão do monarca virtuoso, e portanto exemplar, mas também na sua dimensão humana e complexidade psicológica, com ênfase para aspectos como a sua vida afectiva e familiar. Esta última vertente revestia-se de extrema originalidade, e colocou Guevara em plano de destaque na codificação da novela como género literário e mesmo do romance moderno ${ }^{11}$; contribuiu, por outro lado, para o êxito da obra, ao tornar o imperador uma figura cuja espessura psicológica o tornava próximo dos seus leitores ${ }^{12}$. O carácter porventura demasiado vivo e "realista" de algumas das cartas íntimas atribuídas a Marco Aurélio que se seguiam à biografia, e que ajudaram de modo decisivo a construir o sucesso da edição de 1528 , seriam retiradas por Guevara da edição "oficial” de 1529, continuando contudo a surgir, em apêndice, em edições posteriores, de certa maneira por imposição do público. Seria a edição portuguesa de 1529 a estabelecer essa estrutura, doravante adoptada, como é o caso da edição do Relox de Príncipes de que nos servimos, que refere explicitamente incluir "añadidas ciertas cartas del Emperador Marco Aurelio, que se quitaron en otras Impressiones, que se hizieron antes desta"13.

habían traducido, y todo ello lo baraja con las invenciones de su propia fantasía, que era tan viva, ardiente y amena. Lo que no sabe lo inventa; lo que encuentra incompleto lo suple, y es capaz de relatarnos las conversaciones de tres famosas cortesanas, Laida, Lamia y Flora, como si las hubiese conocido”. Orígenes de la novela, Tomo II, Madrid, 1962, p. 114.

${ }_{10}$ V., por todos Augustin Redondo, op. cit.

11 Francisco Márquez Villanueva e Augustin Redondo, "Burlas y veras...", pp. 176-177.

12 Augustin Redondo, op. cit.,pp. 477-498.

13 Antonio de Guevara, Relox de Príncipes, Prologo general, ed. cit., fol. 19. 
Ambas as obras de Guevara são testemunho da vitalidade, ainda no século XVI, de uma vastíssima literatura de carácter político, moral e pedagógico que, desde a Idade Média, procura sistematizar a "constelação" de virtudes e deveres necessários ao ofício do rei cristão, e fixar a imagem do perfeito governante. Essa já longa tradição medieval dos specula principis ${ }^{14}$, que tem em Erasmo um ilustre continuador com a Institutio Principis Christiani, publicada em 1516, dedicada ao jovem Carlos, futuro imperador e rei de Espanha, sofreria uma ruptura decisiva com a publicação, em 1532, de O Príncipe de Nicolau Maquiavel. Com efeito, a concepção de Maquiavel deixa de privilegiar a representação de um modelo ideal do príncipe de acordo com uma panóplia de virtudes obrigatórias, no cume das quais se encontram as virtudes cristãs, para se inscrever numa reflexão sobre o exercício do poder em função do real. O Príncipe de Maquiavel funda um discurso que, dissociando a política e a moral, se perfila em total antagonismo com o discurso normativo sobre os deveres do príncipe, o exercício do poder e o governo da república ${ }^{15}$.

Mas o alcance destas duas obras de Guevara, particularmente o Relox de Príncipes, ultrapassa largamente o quadro da representação do príncipe ideal e virtuoso, na senda dos specula principis medievais, para se inscrever de forma decisiva, como demonstrou Augustin Redondo, nas realidades políticas do seu tempo ${ }^{16}$. Ou, como sintetiza Davide Bigalli no seu excelente ensaio sobre concepções políticas e utopia na

${ }^{14}$ V., por exemplo, Diego Quaglioni, "Il modello del principe cristiano. Gli 'specula principum' fra Medio Evo e prima Età Moderna”, in Modelli nella Storia del pensiero politico, I, dir. V. I. Comparato, Florença, 1987, pp. 103-122.

15 V., entre outros, Quentin Skinner, The Foundations of Modern Political Thought, I - The Renaissance, Cambridge, 1990, pp. 128-138; idem, Machiavel, Paris, 1989, pp. 45-86; Sebastian di Grazia, Machiavelli all'inferno, Roma-Bari. 1990, espec. pp. 333-388.

${ }^{16}$ Augustin Redondo, op. cit., particularmente pp. 610-694. 
obra de Guevara, na ficção cenográfica de um império romano recriado projectam-se as inquietações e as tensões da Espanha de Carlos $\mathrm{V}^{17}$.

A fortuna não só em Espanha, mas em toda a Europa, no século XVI e mesmo no século XVII, do Libro Áureo de Marco Aurelio e do Relox de Príncipes revelar-se-ia, como afirmámos no início, um fenómeno editorial de proporções extraordinárias, para o qual é dificil encontrar paralelo. Se é evidente exagero afirmar, num quadro comparativo, que só a Bíblia teve maior número de edições ${ }^{18}$, o facto é que a difusão de ambas as obras atinge uma expressão muito importante. Assim, por exemplo, no que diz respeito ao Libro Aureo, podem referenciar-se vinte e uma edições em castelhano, para o período entre 1528 e 1550 , se bem que haja indícios de que este número possa ainda ter sido superior ${ }^{19}$. Se se tiver em conta o número de edições, não só em castelhano, mas das respectivas traduções em francês, italiano ou inglês, verifica-se que as edições conhecidas até 1663 ultrapassam a centena $^{20}$. Quanto às edições em Itália, depois das edições castelhanas de Roma (1531) e Veneza (1532) ${ }^{21}$, contabilizam-se para o período de 1543-1663 vinte e cinco edições, das quais vinte até final do século $\mathrm{XVI}^{22}$.

17 David Bigalli, "Il mito a corte. Pensiero politico e frammenti di utopia in Antonio de Guevara", in Immagini del principi. Ricerche su politica e umanesimo nel Portogallo e nella Spagna del Cinquecento, Milão, 1985, pp. 223-280.

18 V. por exemplo E. Grey, Guevara, a Forgotten Renaissance Author, Haia, 1973, p. IX.

19 Augustin Redondo, op. cit., p. 522.

${ }^{20}$ P. Lino G. Canedo, "Las obras de fray Antonio de Guevara. Ensayo de un catalogo completo de sus ediciones", Archivo Ibero-Americano. Revista de Estudios Historicos, $\mathrm{n}^{\circ}$ temático com o título de Estudios acerca de fray Antonio de Guevara en el IV centenario de su muerte, VI, $n^{\text {os } 22-23 . ~ 1946, ~ e s p e c . ~ p p . ~ 449-~}$ -472; Paul Grendler, Schooling in Renaissance Italy. Literacy and Learning, 1300-1600, Baltimore/Londres, 1991, pp. 422-424, para o caso italiano.

21 P. Lino Canedo, op. cit., pp. 452-453.

22 Ibidem, pp. 467-472. 
Os números relativos ao Relox são igualmente significativos, ultrapassando também a centena o número das suas edições nas várias línguas europeias, entre as quais quinze em italiano entre os anos de 1553 e 1606. Entre 1529 e 1550 houve pelos menos onze edições em castelhano, das quais oito entre 1529 e 1534 . Até 1698 o número total de edições em castelhano foi de dezanove. Lino Canedo contabiliza ainda dez edições em alemão (1574-1665), uma edição em arménio (1738), quarenta e três edições em francês (1540-1608), três edições em holandês (1617-1618), duas em húngaro (1610-1628), seis em inglês (1557-1919), das quais quatro entre 1557 e 1589, onze edições latinas (1601-1746), uma edição em polaco $(1773)^{23}$. Também em Portugal as obras de Antonio de Guevara conheceram assinalável fortuna, com destaque para a edição de Lisboa do Relox, em língua castelhana, ocorrida em Lisboa por ordem de D. João III quase em simultâneo com a primeira edição castelhana ${ }^{24}$.

Em Itália, onde por razões de ordem política a presença espanhola era importante, nomeadamente em Milão, Nápoles e Sićlia, e onde, em Bolonha, Carlos V fora sagrado imperador pelo Papa em 1530, as obras de Guevara, quer o Libro Áureo... quer o Relox de Príncipes, circularam primeiro no original castelhano. A partir de 1542, começam a surgir versões e traduções italianas ${ }^{25}$. Assim, nesse ano é publicada em Roma a primeira versão italiana do Libro Áureo de Marco Aurelio, da autoria de Mambrino Roseo da Fa-

23 P. Lino G. Canedo, op. cit., pp. 472-503.

${ }_{24}$ V., para o caso português, o nosso estudo Imagens do Príncipe. Discurso Normativo e Representação (1525-1549), Lisboa, 1996, pp. 181-190.

25 Augustin Redondo, Antonio de Guevara..., já citado, p. 575; idem, "Le monarque dans les versions italiennes de l'Horloge des princes: de la matière guévarienne au quatrième livre apocryphe de 1562", in Le Pouvoir monarchique et ses supports idéologiques, Etudes réunies par Jean Dufournet, Adelin Fiorato et Augustin Redondo, Paris, 1990, p. 79. 
briano $^{26}$. Mais do que uma verdadeira tradução, a Vita di $M$. Aurelio Imperadore... é uma versão condensada e bastante livre da obra de Guevara, facto justificado pelo próprio Roseo na dedicatória a Paolo Luciasco, em que se afirma a preferência pela imitação de sentido, em detrimento da tradução literal. Esta opção de Roseo situa-se aliás, como observa Lucia Gualdo Rosa, no quadro da polémica humanista iniciada no Quattrocento em torno da tradução ad verbum e ad sententiam ${ }^{27}$.

Apesar do sucesso de que se revestiu - foi objecto de cinco reimpressões em dois $\operatorname{anos}^{28}$ - a versão de 1542 veio a ser definitivamente suplantada pela segunda tradução, da autoria de Sabastiano Fausto da Longiano, publicada em Veneza, em $1544^{29}$. Esta última era, sem dúvida, mais próxima do original $^{30}$, ao contrário da versão de Mambrino Roseo, cujo carácter demasiado livre é severamente criticado e acaba por ser invocado como razão principal para o aparecimento da nova tradução. Esta maior fidelidade ao original estava aliás de acordo com a posição teórica de Fausto da Longiano, autor de um Dialogo [...] del Modo de lo Tradurre d'una in Altra Lingua...(1556) que, inscrevendo-se no debate acima referido, defendia a fidelidade à letra dos textos traduzidos ${ }^{31}$. A tradução de Fausto da Longiano foi a versão mais difun-

26 Vita di M. Aurelio Imperadore, con le alte, E profonde sue sentenze, notabili documenti, ammirabili essempi, E lodevole norma di vivere. V. Paul Grendler, Schooling in Renaissance Italy..., já citado, p. 422.

27 Lucia Gualdo Rosa, "L'Institutio 'del prencipe christiano' de Mambrino Roseo de Fabriano entre Antonio de Guevara et Erasme", in Actes du Colloque International Erasme (Tours,1986). Etudes réunies par Jacques Chomarat, Genebra, 1990, pp. 309-310.

28 Ibidem, p. 311 e p. 322.

29 Vita, gesti, costumi, discorsi, lettere di M. Aurelio Imperatore, sapientissimo filosofo, E oratore eloquentissimo. Con la gionta di moltissime cose, che ne lo spagnuolo non erano, e de le cose spagnuole, che mancavano in la tradottione italiana. V. Paul Grendler, op. cit., p. 422.

30 Paul Grendler, ibidem; Lucia Gualdo Rosa, op. cit., pp. 310-311, e nota 15.

31 V. Lucia Gualdo Rosa, op. cit., p. 310. 
dida do Libro Áureo... em Itália: entre 1544 e 1593 foram feitas vinte e uma edições da Vita, Gesti, Costumi, Discorsi, Lettere di M. Aurelio Imperatore..., havendo a registar ainda cinco edições no século XVII, todas elas impressas em $V_{\text {Veneza }}{ }^{32}$. No currículo em língua vulgar das escolas de Veneza para o ano de 1587, a Vita...di Marco Aurelio era o segundo livro mais citado pelos professores, imediatamente a seguir ao muito difundido Fior di virtü33.

Quanto ao Relox de Príncipes, a primeira tradução para italiano, tradução quase completa e bastante fiel ao original, da autoria de Alfonso de Ulloa, foi publicada em Veneza em 1553. Em 1562 surgiu uma versão alargada, com um suposto quarto livro a que Guevara fazia referência na edição de 1529, mas que não chegou a escrever, e que incidiria sobre as relações do príncipe com a sua corte e casa. Esse quarto livro era na realidade constituído pela tradução de duas outras obras de Guevara: o Aviso de Privados (1539) e o Menosprecio de Corte (1539). Ainda no mesmo ano foi impressa uma nova edição que diferia na composição deste quarto livro apócrifo. Tal como sucedeu com as versões do Libro Áureo, também as edições do Relox de Príncipes se sucederam ao longo do século em número particularmente significativo, quase todas elas feitas em Veneza, sem dúvida um dos lugares privilegiados de difusão da cultura espanhola em Itália ${ }^{34}$.

Tradutor, em versão bastante livre e condensada, como vimos, do Libro Áureo de Marco Aurelio em 1542, Mambrino Roseo da Fabriano publicava no ano seguinte uma obra intitulada Institutione del Prencipe Christiano, dedicada ao cardeal de Carpi, Rodolfo Pio ${ }^{35}$. Tratava-se, na realidade, de

32 Paul Grendler, op. cit., p. 423.

33 Ibidem, p. 300.

34 Augustin Redondo, "Le monarque dans les versions italiennes...", pp. 81-83; Paul Grendler, op. cit., pp. 423-424.

35 Sobre as possíveis razões desta dedicatória, v. Augustin Redondo, ibidem, p. 80 . 
uma selecção e adaptação do Relox de Príncipes de Guevara. Os três livros do Relox - relativos às virtudes e à conduta cristã do príncipe, à sua conduta no quadro da família, ou seja para com a mulher e os filhos, e finalmente ao governo de si próprio como indivíduo e ao governo da repúblicaeram reduzidos a um único, ao qual se dava um título "erasmiano", e as partes relativas à figura mítica do imperador-filósofo, assim como certos episódios, como o emblemático discurso do "vilão do Danúbio", desapareciam ${ }^{36}$. A proximidade da Institutione com o texto do Relox é tão evidente, que Lino Canedo, autor de uma tentativa de catálogo sistemático das edições europeias de Guevara, a inclui no elenco das traduções do Relox de Príncipes em língua italiana ${ }^{37}$.

Recentemente, Lucia Gualdo Rosa pretendeu sublinhar a relativa autonomia da Institutione de Roseo, ressalvando embora o ascendente na sua concepção de obras como o Relox de Príncipes de Guevara e a Institutio Principis Christiani (1516) de Erasmo ${ }^{38}$. Seja como for, a Institutione de Roseo da Fabriano teve um eco assinalável, registando, entre 1543 e 1608, dezasseis edições italianas, e ainda uma tradução para francês (1549) e uma tradução latina $(1608)^{39}$. Mas também uma tradução portuguesa. Com efeito, na Biblioteca da Ajuda, em Lisboa, existe uma tradução manuscrita para português, ainda do século XVI, da Institutione del Prencipe Christiano de Mambrino Roseo da Fabriano, cuja existência referenciámos em estudo anteriormente publicado ${ }^{40}$. A respectiva descrição no Guia dos manuscritos da Ajuda transcreve defeituosamente o respectivo título e omite a identificação do autor,

36 Augustin Redondo, ibidem, pp. 79-80; Lucia Gualdo Rosa, op. cit., p. 311.

37 P. Lino Canedo, op. cit., p. 493.

38 Lucia Gualdo Rosa, op. cit., pp. 316-321; tal não é, manifestamente, a opinião de Redondo. V. "Le monarque dans les versions italiennes...", pp. 79-80.

39 Lucia Gualdo Rosa, op. cit., p. 311 e pp. 323-324.

${ }^{40}$ B. A., cod. $50-V-40$, fols. $1-129 v$. 
que se encontra referido de forma explícita ${ }^{41}$. O título correcto que consta do manuscrito é o seguinte: O Paragon de Vertudes para a Instituiçam de todollos Principes Christãos traduzido de italiano Mambrinus de la Rosa em frances ${ }^{42}$. No Prologo que antecede o tratado, apesar do respectivo fólio estar rasgado, é possível reconhecer a dedicatória ao cardeal de Carpi ${ }^{43}$.

Se bem que não datada, esta tradução anónima da Institutione del Prencipe Christiano de Mambrino Roseo deverá ser posterior a 1549, ano da publicação da sua versão francesa que, como é referido, esteve na base da tradução para português. $\mathrm{O}$ título desta última remete aliás de forma flagrante para o da tradução francesa, da autoria de Jean Mougin, editada em Paris: Le Parangon de Vertu pour l'Institution de tous Princes ${ }^{44}$. Não possuímos no entanto elementos - nomeadamente, como dissemos, o nome do tradutor - que nos permitam situá-la com maior precisão, e eventualmente avaliar do propósito e do destinatário concreto desta tradução portuguesa. E, sem dúvida, esse propósito e esse destinatário existiram, já que a composição destes tratados sobre o príncipe e a realeza é associada, desde a Idade Média, a uma conjuntura particular da vida do príncipe ou do monarca - infầncia, casa própria, casamento, subida ao trono - e a ele expressamente dedicados ${ }^{45}$.

O Paragon de Vertudes... é composto por um só livro, dividido em trinta e seis capítulos, mais um do que o original

41 “Oparaçõis (?) de vertudes para a instituiçam de todollos princepes christãos...". (Traduzido do italiano e francês). ", Manuscritos da Ajuda (Guia), vol. II, p. 667. A única referência que conhecemos a esta obra é feita por Luís de Matos na sua "Introdução" à edição fac-similada do manuscrito das Sentenças para a ensinança e doutrina do príncipe D. Sebastião, Lisboa, 1983, dando-lhe o título de Instituição de tôdolos príncipes cristãos e mencionando a tradução do italiano para francês e a dedicatória ao cardeal Carpi, mas sem aludir à questão da autoria. V. op. cit., p. 19 e nota 29.

42 B. A., cod. 50-V-40, fol. 3.

43 Ibidem, [fol. 1].

${ }^{44}$ Lucia Gualdo Rosa, op. cit., p. 323.

45 V. Ana Isabel Buescu, Imagens do Príncipe..., cit., p. 20 e pp. 33-36. 
italiano, que tem trinta e cinco. A diferença reside no facto de o capítulo XXIII do texto italiano se desdobrar em dois na tradução portuguesa ${ }^{46}$. A sua extensão é, portanto, como dissemos, muito diferente dos três livros do Relox de Príncipes, obra em que visivelmente se inspira. $\mathrm{O}$ tratado abre com uma justificação de carácter político-religioso da monarquia, a que não falta, como é habitual também nestas obras, a necessária distinção entre o bom príncipe e o tirano, distinção em que avulta, como elemento estruturante, o famoso discurso do embaixador dos míticos Garamantes a Alexandre Magno, episódio retirado do Livro I do Relo $x^{47}$. Seguem-se dois capítulos de tom acentuadamente ascético, sobre a miséria da condição humana ${ }^{48}$ da qual, apesar da sua condição singular, também participa o príncipe ${ }^{49}$.

Relevo particular têm, tal como no livro II do Relox de Príncipes - neste ponto sem dúvida o modelo explícito da Institutione - o conjunto das regras e preceitos relativos ao casamento e à educação dos filhos. Essas regras incidem sobre questões que vão desde os cuidados a observar na gravidez, à apologia do aleitamento materno mas também à condição das boas amas, à instrução e boa doutrina que os pais devem dar aos filhos e ao cuidado na escolha dos mestres do príncipe, à importância do conhecimento da religião cristã ${ }^{50}$. Também neste ponto Lucia Gualdo Rosa pretende fazer aproximar a Institutione das doutrinas erasmianas ${ }^{51}$.

46 Edição consultada: Institutione del Prencipe Christiano, Veneza, 1544, exemplar existente na Biblioteca da Ajuda.

47 B.A., cod. 50-V-40, O Paragon de Vertudes..., cap. I "Que de direito natural o princepe he necessario na reepublica: e como a tirania vem de ambiçam”, fols. 3-9.

48 Ibidem, cap. II "Que o princepe deve considerar a miseria humana", fols. 9-14.

49 Ibidem, cap. III "Da miseria de hû princepe", fols. 14-15v.

50 Ibidem, cap. IV-XV, fols. 15v-63.

51 Lucia Gualdo Rosa, op. cit., pp. 319-320. 
Aos preceitos mais imediatamente relativos à criação do príncipe e a aspectos de um itinerário pedagógico destinado a forjar um perfil virtuoso, segue-se o estabelecimento das virtudes que deve possuir, e dos vícios que é necessário evi$\operatorname{tar}^{52}$. Assim, e de acordo com o retrato do governante ideal traçado pela longa tradição dos specula principis, o príncipe deve ser piedoso, sábio, prudente, justo, clemente, misericordioso e liberal, evitando a avareza, a ociosidade, a luxúria e o excesso de ornamento da sua pessoa, de acordo aliás com o que se preceituara quanto à sua educação em criança ${ }^{53}$. Deve reger a república observando as leis antigas ${ }^{54}$, escolher os seus privados entre gente sábia e sensata, afastando de si aduladores, "mexeriqueiros e praguentos" 55 , e ter especial rigor e prudência na escolha dos seus oficiais ${ }^{56}$.

Significativo é o facto de, no elenco circunstanciado destas virtudes não encontrarmos qualquer referência à fortaleza, virtude que, remetendo para a dimensão guerreira, é habitualmente "obrigatória" no conjunto das virtudes consideradas próprias do governante. Com efeito, numa sociedade que valorizava em extremo a função das armas, a imagem do rei é indissociável da fortaleza, virtude associada ao valor militar que o príncipe deve possuir, de acordo com a ancestral concepção do rei como herói guerreiro. Por isso, de forma geral a tratadística sobre o príncipe e a monarquia dão à fortaleza um lugar central no conjunto das virtudes régias. Pelo contrário, no Paragon de Vertudes ... surge um capítulo em que se adverte deverem os príncipes amar e procurar a

52 O Paragon de Vertudes..., cap. XVI-XXXVI, fols. 63-129v.

53 Ibidem, cap. XII "Que o princepe deve dar ordem que seu filho nam seja criado em dilicias", fols. 40-43.

54 Ibidem, cap. XXVI, "Que o princepe deve guardar as leys antigas sem pre-mitir [sic] que outras novas sejam introduzidas na sua reepubrica", fols. 97-99.

55 Ibidem, cap. XXII, fols. 85v-87v.

56 Ibidem, cap. XXXII, fols. 118v-121v. 
$\operatorname{paz}^{57}$. Esta posição parece mais uma vez remeter para a presença tutelar de Guevara, que na sua obra condena de forma radical a guerra, e particularmente a guerra de conquista, num ponto em que a ideologia guevariana encontra, de forma indiscutível, traços do pacifismo erasmiano ${ }^{58}$.

A tradução para português da Institutione del Prencipe Christiano de Mambrino Roseo, que sintetiza, condensa e apropria o Relox de Príncipes é também ela um testemunho da fortuna que a concepção guevariana do príncipe virtuoso alcançou na Europa do século XVI, neste caso através da sua irradiação em Itália, apesar da ruptura ideológica decisiva que a publicação de O Príncipe (1532) de Maquiavel veio significar.

57 Ibidem, cap. XXXV "Que os princepes devem de amar e buscar paz", fols. $126-128 \mathrm{v}$.

${ }^{58}$ V. Augustin Redondo, Antonio de Guevara..., cit. ; Lucia Gualdo Rosa, op. cit., p. 320 . 